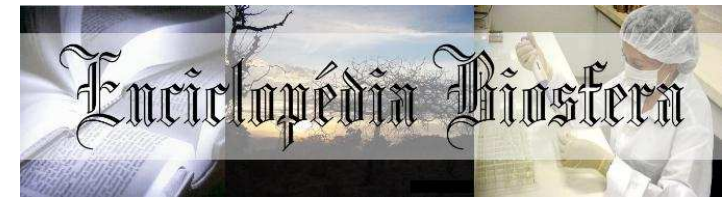

\title{
AVALIAÇÃO DO PROGRAMA NACIONAL DE COOPERAÇÃO ACADÊMICA - PROCAD
}

\section{Elci Vieira de Moura1; Ivan Rocha Neto²}

1 Analista em Ciência e Tecnologia da Coordenação de Aperfeiçoamento de

Pessoal de Nível Superior (Capes) e doutoranda, Educação em Ciências, Universidade Federal do Rio Grande do Sul (UFRGS) Porto Alegre-RS, Brasil.

(elci.moura@capes.gov.br)

2 Prof. Colaborador da Universidade Federal do Rio Grande do Sul

Recebido em: 08/09/2015 - Aprovado em: 14/11/2015 - Publicado em: 01/12/2015

DOI: http://dx.doi.org/10.18677/Enciclopedia_Biosfera_2015_061

\begin{abstract}
Esta pesquisa teve o objetivo de propor uma avaliação do Programa Nacional de Cooperação Acadêmica - PROCAD, a partir da primeira versão (2000) e das versões subsequentes, discutindo em que medida os objetivos de promoção e consolidação de programas de pós-graduação, por meio do incentivo à constituição de redes de cooperação, foram atingidos. A metodologia utilizada foi um levantamento das respostas obtidas por meio de um questionário enviado, por correio eletrônico, aos 603 coordenadores gerais dos projetos PROCAD das edições de 2005 a 2009. Responderam à pesquisa 236 coordenadores. O questionário é constituído de 15 quesitos de natureza qualitativa, contemplando 12 questões fechadas e três abertas, relacionadas aos objetivos e requisitos do PROCAD. Com base na pesquisa realizada, pode-se afirmar que o PROCAD tem estimulado fortemente a interação entre os pesquisadores, a produção de conhecimentos de forma conjunta e a qualificação de pessoal, contribuindo para a criação de redes de cooperação e a consolidação dos programas de pós-graduação. São propostos também, possíveis caminhos para o aperfeiçoamento do Programa.
\end{abstract}

RESUMO

PALAVRAS-CHAVE: Avaliação. CAPES. Cooperação Acadêmica. PROCAD.

\section{ASSESSMENT OF NATIONAL PROGRAM OF ACADEMIC COOPERATION - CAPES}

\begin{abstract}
This research had the purpose of propose an assessment of the National Program of Academic Cooperation - CAPES, from the first version (2000) and subsequent versions, discussing in what measure the goals of promotion of graduate programs, through the incentive of constitution of cooperative networks, were reached. The methodology used was a survey of answers for questionnaire sent by email to 603 project coordinators of PROCAD of 2005-2009 Editions. Two hundred and thirty six coordinators participated in this research. The questionnaire consists of 15 issues of qualitative nature, containing 12 closed and 3 opened questions related to goals and requirements of PROCAD. Based in this research, it can be said that PROCAD has
\end{abstract}


strongly stimulated the interaction among researchers, the joint form of knowledge production and training of personnel, contributing to the creation of cooperative networks and the consolidation of Graduate Programs. Also are proposed possible ways to improve the Program.

KEYWORDS: Assessment. Academic Cooperation. CAPES. PROCAD.

\section{INTRODUÇÃO}

Pelo histórico da pós-graduação brasileira é possível notar que a evolução e os resultados remetem a ações de sujeitos isolados: docentes, pesquisadores, cursos, Programas de Pós-Graduação e universidades (GOMES \& ROCHA NETO, 2011). O apoio a essas ações, geralmente segue o cronograma e a disponibilidade orçamentária das agências de fomento.

Segundo NEVES (1999), no período compreendido entre os anos 80 e 90, as atividades de ciência e tecnologia sofreram com as instabilidades orçamentárias para o setor, assim como a burocratização no desenvolvimento das atividades de fomento pelas agências e órgãos responsáveis. Consequentemente, os programas de fomento criados anteriormente, com o objetivo de alavancar a pós-graduação brasileira, não conseguiam acompanhar a evolução da sociedade. NEVES (1999) destaca que após esse período houve uma conscientização sobre a necessidade de criar novas modalidades de apoio, novos programas de incentivo e garantia da continuidade do fluxo produtivo da ciência e tecnologia, da pesquisa científica, da produção de conhecimentos e da formação de pessoal de nível superior altamente qualificado para atender à demanda decorrente do processo de desenvolvimento e modernização da sociedade.

Uma diferente forma de impulsionar a pesquisa, otimizar recursos e, ainda, diminuir as disparidades regionais alcançou relevância no contexto do fomento às atividades de ciência e tecnologia: os Programas em Rede de Cooperação. De acordo com NEVES (1999) e MOROSINI \& FRANCO (2001), esses programas existem sob a forma de grupos de pesquisa e redes acadêmicas resultando em produções associativas e cooperações institucionais, cuja produção científica é resultado do esforço coletivo e da soma de experiências e conhecimentos dos seus integrantes.

A constatação do crescimento de cooperação entre pesquisadores e programas de pós-graduação na produção do conhecimento científico favorece a compreensão da construção desse conhecimento, que deixa de ser entendido como uma iniciativa individual e passa a fazer parte de redes de relacionamento (ROSSONI \& FILHO, 2009).

Esses grupos e redes colaboram para o fortalecimento de áreas consideradas estratégicas para o desenvolvimento da ciência e tecnologia no país, além de contribuir para a redução das assimetrias regionais. A formação dessas redes de cooperação foi fortemente estimulada por meio de políticas de indução formuladas, especialmente, em atendimento às recomendações do PNPG 2005-2010 (BRASIL, 2005a).

As redes de cooperação, apoiadas por essas ações, se beneficiam com o investimento da pesquisa e, ao mesmo tempo, são ferramentas para a integração dos pesquisadores e das instituições de pesquisa de diversas partes do País (BRASIL, 2005b). Foi nesse contexto que surgiu, a partir do ano de 2000, o Programa Nacional de Cooperação Acadêmica - PROCAD. 
O PROCAD busca propiciar a melhoria dos programas de pós-graduação em todas as áreas do conhecimento, incentivar o intercâmbio científico por meio do apoio à criação de redes de cooperação, favorecer a redução da desigualdade regional na pós-graduação brasileira, estimular a criação de novas áreas nos programas de pós-graduação existentes e aumentar a produção científica e a formação de pessoal de nível superior altamente qualificado (BRASIL, 2010).

O Programa apoia missões de estudos e missões de pesquisa e docência, possibilitando a mobilidade de estudantes, por meio da execução da modalidade de "bolsa sanduíche"1 no país, bem como a mobilidade de docentes dos programas de pós-graduação envolvidos no projeto. Nos itens financiáveis constam ainda, bolsas de doutorado e pós-doutorado no país, passagens aéreas, diárias, auxílio moradia e outras despesas de custeio. Estimula a criação e o fortalecimento de redes de pesquisa entre programas de pós-graduação, com nível de doutorado, considerados consolidados (notas 5, 6 e 7) e outros ainda não consolidados (notas 3 e 4) ou entre programas de pós-graduação consolidados (BRASIL, 2005c).

A partir das recomendações do PNPG 2005-2010, foram estruturadas ações induzidas baseadas em oito eixos. Dois desses eixos são os programas para melhoria geral da qualidade da pós-graduação e programas para redução das assimetrias regionais. O PROCAD ganhou reforço dentre os programas que visam à melhoria geral da qualidade da pós-graduação e outros programas como o Programa Nacional de Cooperação Acadêmica Amazônia - PROCAD Amazônia e o Programa Nacional de Cooperação Acadêmica Novas Fronteiras - PROCAD-NF foram criados no âmbito do eixo voltado à redução das assimetrias regionais (BRASIL, 2005a).

O PROCAD-Amazônia, criado em 2006, no âmbito do Programa Acelera Amazônia, tem por objetivo apoiar à formação de pessoal, a produção de conhecimentos, a mobilidade docente e discente e a fixação de doutores na Amazônia brasileira, por meio de projetos conjuntos de pesquisa, desenvolvidos por instituições de ensino superior da Região Amazônica em parceria com instituições localizadas em outras regiões do país (BRASIL, 2006).

O PROCAD-NF, criado a partir de 2007, busca colaborar com a consolidação de programas de pós-graduação recém-criados, que geralmente são avaliados com nota três e estão localizados nas Regiões Norte, Nordeste e Centro-Oeste, por meio do estímulo à criação de redes de cooperação entre esses programas e outros já consolidados das demais regiões do país (BRASIL, 2010).

Apesar de o PROCAD ter mais de 14 anos de existência e o PNPG 20112020 ter recomendado a continuidade, este não conta ainda com um processo permanente de avaliação. A CAPES realizou uma avaliação das edições do PROCAD 2000 e 2001, que contou com a participação de 15 consultores. Entretanto, foi feita uma avaliação com base em resultados parciais, pois, o Programa estava em fase inicial e não foi possível avaliar a sua eficácia e efetividade. A partir de 2003, foram realizadas avaliações, com base em informações particularizadas do desenvolvimento de cada projeto PROCAD, após dois anos de vigência (CAPES/CPE, 2003).

É necessário instituir uma cultura de avaliação sistemática dos Programas de fomento da CAPES, especialmente o PROCAD, para obter subsídios para melhoria do Programa. Destaca-se, ainda, que uma das recomendações do Plano Nacional

\footnotetext{
${ }^{1}$ Trata-se de bolsa dirigida aos discentes de mestrado e doutorado para realização de estágio de um a doze meses em uma das instituições integrantes da parceria.
} 
de Pós-Graduação - PNPG 2011-2020 é a criação de uma sistemática de acompanhamento e avaliação dos programas induzidos, em decorrência das metas e objetivos estabelecidos pelo referido plano (BRASIL, 2010).

Este artigo teve o objetivo de propor uma avaliação do Programa Nacional de Cooperação Acadêmica - PROCAD, a partir de sua primeira versão (2000) e das versões subsequentes, discutindo em que medida seus objetivos de promoção e consolidação de programas de pós-graduação, por meio do incentivo à constituição de redes de cooperação, foram atingidos. Deverão ser levados em conta os aspectos institucionais, avaliando o PROCAD como instrumento de política pública.

\section{MATERIAL E MÉTODOS}

A metodologia proposta caracteriza-se como um estudo exploratório e descritivo e emprega tanto a abordagem qualitativa, quanto a quantitativa, levando em consideração a complementaridade de tais abordagens (MINAYO, 2012). Para a análise dos dados quantitativos utilizou-se a estatística descritiva. Os dados qualitativos foram estudados por meio da Análise de Conteúdo, de acordo com BARDIN (2011).

Com relação aos meios, elaborou-se um instrumento de consulta, que foi enviado, por correio eletrônico, no período de outubro de 2012 a julho de 2013, aos coordenadores gerais dos projetos PROCAD das edições de 2005 a 2009, que estavam vinculados ao corpo docente de instituições de ensino superior brasileiras. O questionário é constituído de 15 quesitos de natureza qualitativa, contemplando 12 questões fechadas e três abertas, relacionadas aos objetivos e requisitos do PROCAD, visando à avaliação do Programa sob o ponto de vista dos executores. Utilizou-se a escala de Likert com adaptações, estabelecida da seguinte forma: (1) discordo totalmente, (2) discordo parcialmente, (3) não concordo nem discordo, (4) concordo parcialmente, (5) concordo totalmente.

Antes da aplicação, o instrumento foi submetido à validação de um pequeno grupo de coordenadores e avaliadores do PROCAD, para verificação quanto à compreensão das questões. Não fizeram parte da amostra os coordenadores vinculados aos projetos PROCAD das edições de 2000 e 2001, tendo em vista o caráter experimental de tais edições.

\section{RESULTADOS E DISCUSSÕES}

$\mathrm{Na}$ primeira chamada, no PROCAD-2000, como experiência-piloto, foram apoiados 33 projetos, envolvendo 78 equipes. Nos quatro anos de vigência dos projetos foram concedidas 506 bolsas. O investimento total nessa edição foi da ordem de $\mathrm{R} \$ 7.188 .770,76$ (CAPES/CPE, 2004).

$\mathrm{Na}$ Edição do PROCAD-2001 a atuação foi diversificada, incluindo o financiamento de despesas de capital e o apoio a duas modalidades de projetos:

Tipo I - cooperação entre equipes, sendo uma denominada Líder, vinculada a Programa de Doutorado de uma única Instituição de Ensino Superior com nota igual ou superior a 5 e as demais Associadas, constituídas por pesquisadores estudantes e técnicos de um núcleo para a criação de Programa de pós-graduação stricto sensu e/ou programa com nota igual ou inferior a 4.

Tipo II - cooperação entre equipes vinculadas a Programas de Doutorado com nota igual ou superior a 5 (BRASIL, 2001). 
Nessa edição foram contemplados 85 projetos, contando com a participação de 217 equipes. Foram concedidas 903 bolsas nos níveis de mestrado sanduíche, doutorado sanduíche e pós-doutorado. O investimento total foi da ordem de $R \$$ 19.496.196,89 (CAPES/CPE, 2015a).

Em 2005, a CAPES lançou uma nova edição do PROCAD, onde concorreram 370 projetos (315 do Tipo I e 55 do Tipo II). Vale ressaltar que cada projeto é constituído por duas a quatro equipes, de diferentes IES. Assim, foram aprovados 132 projetos, beneficiando 337 equipes. O PROCAD 2005 teve um investimento total de $R \$ 32.204 .045,43$ para os quatro anos de desenvolvimento dos projetos, exclusivamente, em despesas de custeio (CAPES/CPE, 2010b).

Cabe esclarecer que nas edições anteriores ao PROCAD 2005 a CAPES apoiou todos os projetos que foram recomendados na análise de mérito. Em 2005, por restrições orçamentárias, foram aprovados apenas os projetos recomendados na análise de mérito com prioridade máxima e parte dos projetos recomendados com prioridade média. Assim, em 2006 a CAPES implementou a Edição PROCAD Amazônia, visando ao atendimento das diretrizes do PNPG 2005-2010, que reforçaram a necessidade de ações voltadas à redução das assimetrias regionais, bem como ao apoio complementar à Edição PROCAD 2005, que financiou apenas $36 \%$ dos projetos submetidos ao edital (CAPES, 2010b).

No PROCAD Amazônia tiveram prioridade as instituições pertencentes à Amazônia brasileira (além dos Estados que compõem a Região Norte, foram incluídos os Estados do Maranhão e Mato Grosso). O Programa favorece a consolidação equilibrada da pós-graduação brasileira. A parceria é estabelecida entre um programa de pós-graduação com nota 5 e os demais com nota 3 ou 4, ou ainda um núcleo para futura proposição de programa de pós-graduação stricto sensu, sendo obrigatória a participação de pelo menos uma equipe da Região Amazônica (BRASIL, 2006).

Nessa edição foram apoiados 28 projetos, envolvendo 56 equipes. Foram concedidas 25 bolsas de mestrado sanduíche, 20 de doutorado sanduíche e 18 de pós-doutorado. O investimento total foi da ordem de $R \$ 6.241 .898,32$. A partir desse edital, a CAPES decidiu não conceder bolsa de doutorado pleno, por meio do PROCAD, tendo em vista que os programas tradicionais da Agência já contemplam tal benefício. Além disso, a modalidade de bolsa sanduíche é mais apropriada ao PROCAD, uma vez que viabiliza a mobilidade dos alunos entre as equipes parceiras (CAPES/CPE, 2010a).

Em 2007 foi lançado o PROCAD-Novas Fronteiras, atendendo de forma especial, as Regiões Norte, Nordeste e Centro-Oeste. Nessa edição foram apoiadas as áreas temáticas de Ciências Agrárias; Ecologia e Meio Ambiente; Biotecnologia; Engenharias; Computação; Ensino de Ciências e Matemática e Saúde Coletiva. Foram financiados 82 projetos, contemplando 185 equipes. O valor total do financiamento foi de $\mathrm{R} \$ 1$ 19.186.811,98. Foram implementadas 187 bolsas de mestrado sanduíche, 51 de doutorado sanduíche e 33 de pós-doutorado (CAPES/CPE, 2010a).

Em 2007 foi publicado, também, o Edital PROCAD, em nível nacional, apoiando todas as áreas do conhecimento e instituições de ensino superior ou de pesquisa de todas as regiões do país. Nessa edição foram financiados 207 projetos, compostos por 563 equipes. O valor total investido foi da ordem de 49.431.988,99. Foram concedidas 564 bolsas de mestrado sanduíche, 263 de doutorado sanduíche e 167 de pós-doutorado (CAPES/CPE, 2010a). 
A partir de 2008 foram lançadas mais duas edições do PROCAD Novas Fronteiras (edições 2008 e 2009). No PROCAD Novas Fronteiras 2008 foram contemplados 110 projetos, beneficiando 227 equipes. $O$ valor total do edital foi da ordem de $\mathrm{R} \$ 22.015 .709,49$. Foram concedidas nesse edital, 227 bolsas de mestrado sanduíche, 59 de doutorado sanduíche e 135 de pós-doutorado. $\mathrm{Na}$ Edição de 2009 foram apoiados 126 projetos constituídos de 325 equipes, contando com um financiamento total de $\mathrm{R} \$ 34.938 .596,90$. No âmbito do PROCAD Novas Fronteiras 2009 foram concedidas 912 bolsas de mestrado sanduíche, 321 de doutorado sanduíche e 320 de pós-doutorado. Nessa edição houve um aumento no valor máximo de financiamento de cada projeto, em relação às edições anteriores, passando de $R \$ 250.000,00$ para $R \$ 300.000,00$ (CAPES/CPE, 2010a).

Em 2013 a CAPES lançou outra edição do PROCAD, em nível nacional, que, apesar de contar com um financiamento total de $R \$ 77.314 .815,00$, valor bem superior aos valores estabelecidos para os editais anteriores, está financiando apenas 100 projetos, menos de $50 \%$ do total de projetos aprovados na chamada do PROCAD de 2007 (BRASIL, 2013a).

No Quadro 1 a seguir, são apresentados o total de projetos apoiados, o número de equipes envolvidas e o valor total do financiamento, em cada edição do PROCAD.

QUADRO 1: Investimentos PROCAD (2000 a 2013)

\begin{tabular}{|c|c|c|c|c|}
\hline Edital & Edição & $\begin{array}{c}\text { Projetos } \\
\text { Aprovados }\end{array}$ & Equipes & Investimentos (R\$) \\
\hline PROCAD & 2000 & 33 & 78 & $7.188 .770,76$ \\
\hline PROCAD & 2001 & 85 & 217 & $19.496 .196,89$ \\
\hline PROCAD & 2005 & 132 & 337 & $32.204 .045,43$ \\
\hline PROCAD Amazônia & 2006 & 28 & 56 & $6.241 .898,32$ \\
\hline PROCAD & 2007 & 207 & 563 & $49.431 .988,99$ \\
\hline PROCAD NF & 2007 & 82 & 185 & $19.186 .811,98$ \\
\hline PROCAD NF & 2008 & 110 & 227 & $22.015 .709,49$ \\
\hline PROCAD NF & 2009 & 126 & 325 & $34.938 .596,90$ \\
\hline PROCAD & 2013 & 100 & 313 & $77.314 .815,00$ \\
\hline
\end{tabular}

Fonte: Dados DPB/CGPE/CPE (Elaboração dos autores )

O Edital PROCAD 2013 apresentou algumas novidades, tais como a concessão de bolsa plena de iniciação científica (duração 24 meses), a extinção das bolsas de mestrado sanduíche e doutorado sanduíche e a gestão financeira sob a responsabilidade exclusiva do coordenador geral do projeto. Foi criado também, um auxílio para custear as despesas dos docentes e discentes para participação em eventos científicos ou acadêmicos. Essa inovação vem, especialmente, ao encontro das necessidades dos alunos que são impedidos legalmente de receber diárias por meio dos projetos PROCAD e ficavam impossibilitados de participar de tais eventos, pois, não tinham nenhuma ajuda para custeio de sua hospedagem, alimentação e 
deslocamento. O valor máximo de cada projeto passou para $R \$ 835.200,00$ (BRASIL, 2013a).

No Edital PROCAD 2013 foram submetidas 256 propostas. Desse total, 220 projetos foram recomendados na análise de mérito. Por restrições orçamentárias, foram apoiadas somente 100 propostas, sendo o custo total do edital de $\mathrm{R} \$ 77.314 .815,00$ (CAPES/CPE, 2015b). Entretanto, com o mesmo montante seria possível atender todos os projetos recomendados no mérito, se o financiamento de cada projeto fosse estabelecido em até $R \$ 351.430,00$.

No Quadro 2 a seguir, é apresentada a concessão das bolsas no âmbito do PROCAD, nas edições de 2000 a 2013.

QUADRO 2: Bolsas concedidas PROCAD (2000 a 2013)

\begin{tabular}{|c|c|c|c|c|c|c|c|}
\hline \multirow[b]{2}{*}{ Edital } & \multirow[b]{2}{*}{ Edição } & \multicolumn{6}{|c|}{ Bolsas } \\
\hline & & $\begin{array}{l}\text { Iniciação } \\
\text { Científica }\end{array}$ & $\begin{array}{l}\text { Mestrado } \\
\text { Sanduíche }\end{array}$ & $\begin{array}{l}\text { Doutorado } \\
\text { Sanduíche }\end{array}$ & $\begin{array}{c}\text { Doutorado } \\
\text { Pleno }\end{array}$ & $\begin{array}{c}\text { Pós- } \\
\text { doutorado }\end{array}$ & Total \\
\hline PROCAD & 2000 & & 191 & 105 & 137 & 73 & 506 \\
\hline PROCAD & 2001 & & 376 & 267 & 260 & - & 903 \\
\hline PROCAD & 2005 & & 446 & 295 & 148 & 128 & 1.017 \\
\hline $\begin{array}{l}\text { PROCAD } \\
\text { Amazônia }\end{array}$ & 2006 & & 25 & 20 & - & 18 & 63 \\
\hline PROCAD & 2007 & & 564 & 263 & - & 167 & 994 \\
\hline $\begin{array}{c}\text { PROCAD } \\
\text { NF }\end{array}$ & 2007 & & 187 & 51 & - & 33 & 271 \\
\hline $\begin{array}{c}\text { PROCAD } \\
\text { NF }\end{array}$ & 2008 & & 227 & 59 & - & 135 & 421 \\
\hline $\begin{array}{c}\text { PROCAD } \\
\text { NF }\end{array}$ & 2009 & & 912 & 321 & - & 320 & 1.553 \\
\hline PROCAD & 2013 & 3.192 & - & - & - & 560 & 3.752 \\
\hline
\end{tabular}

Fonte: Dados DPB/CGPE/CPE- Elaboração dos autores.

Os resultados relativos às questões fechadas da pesquisa de opinião aplicada aos coordenadores de projetos PROCAD são apresentados a seguir. Do total de 603 questionários aplicados aos coordenadores de projetos vinculados às edições PROCAD (2005 e 2007), PROCAD Amazônia 2006 e PROCAD NF (2007, 2008 e 2009) 236 responderam à consulta, o que representa $39 \%$ do grupo de estudo.

O maior número de respondentes pertence ao Edital PROCAD-NF 2007. De um total de 72 questionários aplicados, 46 responderam à consulta, ou seja, 63,89\% dos coordenadores consultados. Pode-se inferir que o término da vigência do referido edital, ocorrido em 2012, mesmo período de aplicação do questionário, facilitou a avaliação das atividades por parte dos coordenadores, resultando em um número mais expressivo de respostas. Em 2010, foi aplicada uma pesquisa semelhante, que apresentou $32 \%$ de respondentes (GOMES \& ROCHA NETO, 2011).

Em seguida, no Edital do PROCAD Amazônia, de um total de 14 questionários aplicados, 8 coordenadores responderam à consulta, o que representa $57,14 \%$ do grupo de estudo. Pode-se compreender que 0 fato de o Edital contemplar, de forma especial, uma região mais carente de formação de pessoal em relação às demais regiões do País, favoreceu o reconhecimento, por parte dos beneficiários do Programa, da importância de tal política pública e, consequentemente, o interesse em contribuir com a pesquisa.

A Edição PROCAD NF 2008 teve 39 respondentes, de um total de 88 questionários aplicados, representando $44,32 \%$ dos coordenadores consultados. A seguir, a Edição PROCAD 2007 apresentou 69 respondentes, de um total de 178 
questionários aplicados, ou seja, 38,76\% do grupo de estudo. O PROCAD NF 2009 apresentou resultados próximos ao PROCAD 2007, de um total de 123 questionários, 46 responderam à consulta, representando $37,40 \%$ dos coordenadores consultados.

O Edital PROCAD 2005 teve o menor número de respondentes em relação aos demais editais do PROCAD. De um total de 128 questionários aplicados, somente 28 foram respondidos, ou seja, $21,88 \%$ do grupo de estudo. Pode-se compreender que o baixo número de respostas foi ocasionado pelo fato do edital ter finalizado sua vigência desde 2010, dificultando o preenchimento do questionário por parte dos ex-coordenadores, uma vez que já se encontravam envolvidos com outros projetos e demais atividades acadêmicas.

Por outro lado, verificou-se que $79 \%$ das respostas obtidas, por meio do questionário aplicado, ficaram entre as opções concordo parcialmente ou concordo totalmente, o que demonstra que o Programa PROCAD tem alcançado os principais objetivos que nortearam a sua criação, exceto com relação aos itens 9 e 12 do questionário, conforme abaixo.

a) Item 9 - As metas prometidas nos projetos são muito otimistas: apesar de $53 \%$ das respostas estarem situadas nas escalas concordo parcialmente $(39,83 \%)$ e concordo totalmente $(12,71 \%)$, responderam não concordo nem discordo $(14,83 \%)$, discordo parcialmente $(21,18 \%)$ e discordo totalmente $(11,44 \%)$, totalizando $47 \%$. Por outro lado, diferente das demais afirmações, o fato da afirmação de ํo 9 ter alcançado um número menor de respostas em relação aos demais itens situados nas opções concordo parcialmente e concordo totalmente é positivo, pois, a expectativa do PROCAD é o estabelecimento de metas realistas. Comparando esses dados com os resultados de avaliações intermediárias é possível observar que uma parte considerável dos coordenadores de projetos não conseguiu atingir plenamente as metas estabelecidas e, embora tenham apresentado outras justificativas para o não cumprimento das mesmas, tais como atraso no repasse, necessidade de remanejamento de rubricas, etc., a falta de um planejamento mais realista, por parte dos coordenadores, deve também ser considerada. Observa-se que alguns coordenadores, ao submeterem um projeto a CAPES para avaliação, apresentam um orçamento com quantidades superestimadas de bolsas, auxílios moradia, missões de docência e outros itens, o que pode inviabilizar a execução de forma plena.

b) Item 12 - A divulgação dos resultados da análise das prestações de contas tem sido feita com rapidez: $50 \%$ das respostas foram concordo parcialmente $(29,23 \%)$ e concordo totalmente $(20,33 \%)$, responderam não concordo nem discordo (16,10\%), discordo parcialmente $(19,49 \%)$, discordo totalmente $(13,55 \%)$ e $1,27 \%$ deixaram o quesito em branco, totalizando $50 \%$. É possível constatar, por meio de dados disponíveis no setor de prestação de contas da CAPES, que cerca de $60 \%$ dos processos de prestação de contas relativos ao PROCAD enviados a CAPES, até o ano de 2013, ainda estão em fase de análise. A demora na análise das prestações de contas gera dificuldades para os coordenadores de projetos, pois, muitos equívocos ocorridos na execução dos recursos poderiam ser sanados no decorrer da vigência do projeto, caso o resultado da análise das prestações de contas fossem divulgados em tempo hábil.

Os resultados relativos às questões fechadas da pesquisa de opinião aplicada aos coordenadores de projetos PROCAD são apresentados no Quadro 3, a seguir. 
QUADRO 3 - Avaliação dos coordenadores de Projetos das Edições PROCAD (2005 e 2007); PROCAD Amazônia; PROCAD NF (2007, 2008 e 2009).

\begin{tabular}{|c|c|c|c|c|c|c|}
\hline Afirmações & $\begin{array}{l}\text { Discordo } \\
\text { totalmente }\end{array}$ & $\begin{array}{l}\text { Discordo } \\
\text { parcialment } \\
\mathrm{e}\end{array}$ & \begin{tabular}{|c|} 
Não \\
concord \\
o nem \\
discordo \\
\end{tabular} & $\begin{array}{l}\text { Concordo } \\
\text { parcialme } \\
\text { nte }\end{array}$ & $\begin{array}{c}\text { Concordo } \\
\text { totalmente }\end{array}$ & $\begin{array}{l}\text { Não } \\
\text { informa } \\
\text { do }\end{array}$ \\
\hline $\begin{array}{l}\text { 1. Os prazos estabelecidos } \\
\text { pelo PROCAD para as } \\
\text { missões de docência estão } \\
\text { condizentes com as } \\
\text { necessidades do projeto. }\end{array}$ & 0 & 13 & 13 & 70 & 139 & 1 \\
\hline $\begin{array}{l}\text { 2. Os prazos estabelecidos } \\
\text { pelo PROCAD para as } \\
\text { missões de pesquisa estão } \\
\text { condizentes com as } \\
\text { necessidades do projeto. }\end{array}$ & 2 & 13 & 6 & 70 & 144 & 1 \\
\hline $\begin{array}{l}\text { 3. A duração das missões de } \\
\text { estudos definida pelo } \\
\text { PROCAD tem atendido às } \\
\text { necessidades do projeto. }\end{array}$ & 4 & 16 & 10 & 61 & 145 & 0 \\
\hline $\begin{array}{l}\text { 4. As missões têm de fato } \\
\text { contribuído para o } \\
\text { fortalecimento da } \\
\text { cooperação entre as equipes } \\
\text { participantes do projeto. }\end{array}$ & 1 & 7 & 7 & 43 & 177 & 1 \\
\hline $\begin{array}{l}\text { 5. O projeto tem contribuído } \\
\text { para o aumento da produção } \\
\text { científica dos programas } \\
\text { cooperantes. }\end{array}$ & 4 & 10 & 9 & 77 & 135 & 1 \\
\hline $\begin{array}{l}\text { 6. O Programa está } \\
\text { favorecendo a diminuição da } \\
\text { desigualdade regional na } \\
\text { pós-graduação. }\end{array}$ & 4 & 7 & 24 & 70 & 130 & 1 \\
\hline $\begin{array}{l}\text { 7. A formação de redes } \\
\text { cooperativas entre } \\
\text { Programas estimulada pelo } \\
\text { PROCAD tem favorecido o } \\
\text { avanço no desenvolvimento } \\
\text { científico e a formação de } \\
\text { pessoal qualificado }\end{array}$ & 3 & 6 & 18 & 56 & 151 & 2 \\
\hline $\begin{array}{l}\text { 8. Os recursos financeiros } \\
\text { têm sido suficientes para o } \\
\text { alcance das metas. }\end{array}$ & 8 & 35 & 21 & 84 & 87 & 1 \\
\hline $\begin{array}{l}\text { 9. As metas prometidas nos } \\
\text { projetos são muito otimistas. }\end{array}$ & 27 & 50 & 35 & 94 & 30 & 0 \\
\hline $\begin{array}{l}\text { 10. A gestão do Programa } \\
\text { tem sido feita de forma ágil. }\end{array}$ & 4 & 18 & 27 & 84 & 99 & 4 \\
\hline $\begin{array}{l}\text { 11. A gestão do Programa } \\
\text { tem sido feita de forma } \\
\text { flexível. }\end{array}$ & 10 & 19 & 22 & 80 & 100 & 5 \\
\hline $\begin{array}{l}\text { 12. A divulgação dos } \\
\text { resultados da análise das } \\
\text { prestações de contas tem } \\
\text { sido feita com rapidez. }\end{array}$ & 32 & 46 & 38 & 69 & 48 & 3 \\
\hline TOTAIS & 99 & 240 & 230 & 858 & 1385 & 20 \\
\hline
\end{tabular}

Fonte: Pesquisa com coordenadores (Elaboração dos autores). 
Foram analisadas as respostas às questões abertas do questionário aplicado aos coordenadores de projetos PROCAD. Na sequência de cada pergunta estão listados os principais benefícios, problemas e sugestões relacionadas ao Programa, segundo os coordenadores dos projetos consultados.

13 - Do seu ponto de vista, quais os benefícios que os projetos PROCAD têm ensejado aos programas de pós-graduação participantes?

a) A cooperação entre docentes e discentes de diferentes programas de pósgraduação propicia as condições para a troca de experiências, a formação de redes de pesquisadores, o aumento da qualidade e da quantidade da produção científica e das dissertações/teses, a consolidação dos grupos e das linhas de pesquisa, a criação de novos cursos, o uso compartilhado de laboratórios, a continuidade das pesquisas por parte dos discentes em programas de doutorado ou pós-doutorado das instituições de ensino superior parceiras e o bom nível de formação de recursos humanos;

b) O financiamento de material de consumo e reagentes para os programas de pós-graduação e autonomia na execução dos gastos e prestação de contas;

c) O fortalecimento das notas dos programas de pós-graduação;

d) Contribui para a redução das assimetrias regionais na pós-graduação brasileira;

e) Propicia experiência para os programas em consolidação e abrangência nacional para os programas consolidados;

f) Permite a mobilidade entre alunos e docentes, por meio das missões de pesquisa e estudo;

g) Estimula a participação em eventos científicos nacionais.

\section{4 - Quais os principais problemas em relação à gestão do PROCAD?}

a) Não foram identificados problemas, o programa funciona de forma satisfatória;

b) A falta de financiamento para a aquisição de equipamentos e a impossibilidade de utilizar os recursos de um item financiável para outro;

c) A demora na análise da prestação de contas e divulgação do seu resultado;

d) O baixo valor das diárias e do auxílio moradia em relação aos preços de hotéis, transporte e alimentação;

e) A gestão financeira de responsabilidade única do coordenador, o que é uma sobrecarga;

f) Falta de sistema informatizado e site específico para auxiliar no gerenciamento dos projetos;

g) Impossibilidade de pagamento de diárias para alunos e falta de flexibilidade na duração das missões;

h) Dificuldade na gestão da conta pesquisador do Banco do Brasil, que não permite acesso on-line;

\section{5 - Quais são as suas sugestões para o aperfeiçoamento da gestão do PROCAD?}

a) O formato do PROCAD é adequado e deve ter continuidade;

b) Permitir a cooperação entre programas 3 e 4 das regiões Norte, Centro-Oeste e Nordeste, e incluir parcerias em nível de laboratórios e grupos de pesquisa; 
c) Manter o diálogo aberto com os coordenadores, por meio de reuniões presenciais ou por vídeo conferência e visitas técnicas pela CAPES, durante a execução dos projetos;

d) Financiar equipamentos de pequeno porte, viagens para congressos da área e pequenas obras;

e) Simplificar os relatórios de prestação de contas e agilizar sua análise;

f) Flexibilizar a execução dos recursos e a duração das missões de estudo;

g) Criar um sistema informatizado para o PROCAD e financiar a produção e manutenção de um site interinstitucional para divulgação das atividades;

h) Aumentar o valor das diárias, do auxílio moradia e da parcela de custeio;

i) Mudar o tipo de conta bancária, permitindo o uso da internet;

Com base nas principais observações feitas pelos coordenadores vinculados aos projetos PROCAD de todas as edições, são feitas algumas considerações, a seguir.

Observa-se que a maioria dos benefícios mencionados pelos coordenadores dos editais PROCAD é alcançada, especialmente, devido ao trabalho realizado por meio de rede de cooperação acadêmica. A partir da criação do PROCAD o trabalho em rede passou a ser estimulado fortemente pela CAPES, especialmente por meio dos programas vinculados à Coordenação Geral de Programas Estratégicos da Diretoria de Programas e Bolsas no País. Destaca-se que o PROCAD foi o primeiro programa da CAPES a implantar a bolsa sanduíche no País e o auxílio moradia, nos níveis de mestrado, doutorado e iniciação científica. Posteriormente, diversos programas passaram a adotar esses benefícios, que possibilitam a mobilidade dos alunos de graduação e de pós-graduação participantes dos projetos. O PROCAD também foi o pioneiro na concessão de bolsas de pós-doutorado no País. Com base nessa experiência foram criados programas específicos para concessão de bolsas de pós-doutorado no País, por exemplo, o Programa Nacional de Pós-Doutorado PNPD.

A CAPES reserva em seu orçamento anual um montante significativo para renovação dos projetos PROCAD e para lançamento de novos editais. Desde 2007 a Agência tem apoiado os projetos PROCAD que são recomendados na análise de mérito, exceto na Edição de 2013, que teve a quantidade de projetos apoiados reduzida, entretanto, o valor do financiamento dos projetos foi, proporcionalmente, superior ao montante destinado às demais edições.

O PROCAD adotou o instrumento Auxílio Financeiro a Projeto Educacional e de Pesquisa - AUXPE, que é firmado entre a CAPES e o coordenador do projeto, possibilitando a descentralização dos recursos e maior agilidade na sua utilização. Atualmente, a maioria dos programas da CAPES, que apoiam projetos de pesquisa, utiliza o AUXPE.

A participação no PROCAD tem influência direta no sistema de avaliação dos Programas de Pós-Graduação, que utiliza um item que trata a respeito da inserção social. Um programa mais qualificado que auxilia um novo ou que enfrenta mais dificuldades recebe uma pontuação maior. O Programa que enfrenta mais dificuldades também é beneficiado quando reconhece as limitações e procura estabelecer uma parceria para desenvolver potencialidades. Outro quesito utilizado é o da solidariedade, ou seja, os programas que pretendem obter notas 6 ou 7 precisam colaborar com os cursos de notas 3 e 4 .

O PROCAD e outros Programas da CAPES tais como, o Mestrado Interinstitucional - MINTER e o Doutorado Institucional - DINTER são excelentes 
ferramentas para alcançar tais requisitos, entretanto, as comissões de área deveriam dar maior importância aos itens relacionados à inserção social e solidariedade no processo de avaliação dos programas de pós-graduação.

Com relação aos principais problemas destacados pelos coordenadores de todas as edições do PROCAD, a seguir, são feitas algumas considerações. Os recursos do PROCAD estão distribuídos nas rubricas relativas às bolsas, auxílio moradia, passagens, diárias e parcela fixa (recursos de custeio para outras despesas do projeto). O remanejamento entre as rubricas de passagens, diárias e parcela fixa pode ocorrer desde que seja solicitado e aprovado pela CAPES. Entretanto, não é permitido o remanejamento de recursos de bolsa e auxílio moradia para passagens, diárias e parcela fixa, bem como destas últimas despesas para bolsas de estudo e auxílio moradia, tendo em vista que os valores relativos às bolsas e auxílios moradia ficam retidos na CAPES, para pagamento diretamente aos bolsistas e os demais recursos são transferidos ao coordenador do projeto, por meio do AUXPE.

Os valores de diárias adotados nos editais fomentados pela CAPES são estabelecidos pelo Decreto no 6.907/2009, que trata da concessão de diárias para servidores públicos e colaboradores eventuais, para indenização de despesas com hospedagem, locomoção e alimentação, durante os afastamentos de interesse da administração pública, fora do local de exercício (BRASIL, 2009). Os valores estão defasados em relação aos valores praticados pelo sistema hoteleiro. O Conselho Nacional de Desenvolvimento Científico e Tecnológico - CNPq resolveu tal dificuldade criando a Resolução Normativa no 040/2013, que estabelece valores de diárias para apoiar a participação de pesquisadores, membros de equipe e convidados no interesse da pesquisa, no país e no exterior, em atividades científicas, tecnológicas e de inovação relacionadas a auxílios individuais e bolsas de curta duração (BRASIL, 2013b). É recomendável que a CAPES crie um instrumento semelhante, para facilitar a mobilidade dos docentes nos programas de apoio à pós-graduação criados pela Agência.

O valor do auxílio moradia, até março de 2013, correspondia à metade do valor da bolsa, de acordo com o nível do curso. A CAPES alterou, a partir de abril de 2013, o valor do auxílio moradia para o valor único de $R \$ 1.100,00$, para os níveis de mestrado, doutorado e iniciação científica, conforme Memorando no 79/2014, datado de 19/04/2014, assinado pelo Diretor de Programas e Bolsas no País.

Destaca-se que existe uma grande quantidade de prestações de contas aguardando análise, tendo em vista o número significativo de auxílios concedidos aos pesquisadores. A CAPES criou, por meio da reestruturação da DPB, a Divisão de Acompanhamento - DAC, que é responsável pela análise técnica de todas as prestações de contas dos auxílios concedidos pela referida Diretoria. Além disso, foi instituída uma comissão para análise das prestações de contas, para tornar mais ágil o trabalho.

Visando simplificar o processo de prestação de contas, a CAPES criou, em 16 de maio de 2013, o SIPREC - Sistema de Prestação de Contas online da CAPES, disponível na página eletrônica da Agência. Os coordenadores de projetos, implantados a partir de 2013, estão utilizando o referido sistema.

As edições do PROCAD, lançadas no período de 2000 a 2009, não contaram com um sistema de gerenciamento eletrônico, o que dificulta bastante 0 acompanhamento dos projetos por parte dos beneficiários e também por parte da equipe técnica da CAPES. A partir da Edição de 2013, foi possível utilizar a plataforma eletrônica, Sistema Integrado CAPES - SICAPES, criado para submissão 
de propostas. As demais etapas do sistema ainda estão em fase de desenvolvimento.

Com relação à vedação de pagamento de diárias a alunos, as orientações são da Controladoria-Geral da União - CGU. Faz jus à percepção de diárias, conforme o Manual da CGU, o servidor civil da administração federal direta, autárquica e fundacional que se desloca, a serviço, da localidade onde tem exercício para outro ponto do território nacional, ou para o exterior, bem como o colaborador eventual convidado a prestar serviços ou participar de eventos de interesse dos órgãos ou entidades da Administração Pública Federal (BRASIL, 2012). Entretanto, na Edição do PROCAD 2013 foi instituído um auxílio para custear despesas de hospedagem, alimentação e deslocamento para participação de discentes em eventos científicos ou acadêmicos.

Os editais PROCAD não financiam despesas de capital devido ao orçamento global da CAPES, que tem apenas $10 \%$ destinados a tais despesas. A CAPES criou editais específicos para o financiamento de equipamentos, visando complementar o apoio concedido por meio dos editais PROCAD e outros voltados para a formação de recursos humanos.

As edições do PROCAD, lançadas até 2009, limitavam a parcela fixa a $R \$$ $10.000,00$, por ano, para cada equipe do projeto, o que gerou várias solicitações de remanejamento de recursos de outros itens para parcela fixa. No Edital PROCAD 2013 não foi utilizada a denominação "parcela fixa" e foi estabelecido o montante de $\mathrm{R} \$ 90.000,00$ por ano, para as despesas de custeio do projeto, tais como: passagens, diárias, material de consumo, serviço de terceiro, etc. Houve um aumento significativo do valor destinado às despesas de custeio em relação aos editais anteriores, considerando que o valor total de tais despesas pode alcançar até $\mathrm{R} \$ 360.000,00$ por projeto.

Todos os respondentes reconhecem que o PROCAD é uma ação importante para o desenvolvimento da pesquisa e da pós-graduação, são favoráveis à continuidade do Programa e apresentam críticas e sugestões visando ao aperfeiçoamento do PROCAD. Algumas das sugestões apresentadas pelos coordenadores já foram implementadas pela CAPES. Entretanto, as mudanças sugeridas pelos respondentes, ainda não incorporadas ao Edital PROCAD 2013 e mencionadas a seguir, poderiam ser consideras na elaboração do próximo edital do Programa.

A redução da duração das missões discentes poderia possibilitar a mobilidade de um número maior de alunos, pois, muitos discentes não têm condições de se afastar por prazo igual ou superior a um mês. Além disso, muitas missões são programadas para execução em prazo inferior a 30 dias. O valor do auxílio moradia poderia ser pago proporcionalmente ao período de permanência do aluno na Instituição parceira.

O apoio à aquisição de material permanente fortaleceria a estrutura de pesquisa científica e tecnológica dos programas de pós-graduação, especialmente daqueles pertencentes às regiões Norte, Nordeste e Centro-Oeste, contribuindo, de forma significativa, para a diminuição das assimetrias regionais.

A possibilidade de apoiar a cooperação entre programas de pós-graduação com notas 3 e 4 das regiões Norte, Nordeste e Centro-Oeste poderia ser considerada, pois, a quantidade de programas com notas superior a 5 é pequena em relação ao número de programas recomendados com nota inferior a essa. Além disso, essa parceria poderia ter mais chance de continuidade, mesmo após o encerramento do projeto, devido à proximidade geográfica, bem como o anseio de 
superação das limitações e desenvolvimento das potencialidades por parte desses programas.

A necessidade de acelerar a divulgação dos resultados da análise das prestações de contas deveria ser o principal problema a ser estudado pela CAPES. Os procedimentos de análise e divisão das tarefas relativas à prestação de contas precisam ser revistos, para reforçar a transparência dos gastos públicos e, consequentemente, evitar problemas com os órgãos de controle.

A realização de seminários e reuniões, presenciais ou por vídeo conferência, com os gestores da CAPES e os coordenadores dos projetos PROCAD, possibilitaria o esclarecimento de dúvidas sobre a execução dos recursos. Além disso, os coordenadores teriam a oportunidade de apresentar projetos e os resultados alcançados, fortalecendo a interação entre os pesquisadores e estabelecendo novas parcerias.

A criação de uma página na internet com os dados de todos os projetos financiados pelas edições do PROCAD seria uma excelente ferramenta para a divulgação das atividades desenvolvidas no âmbito de cada projeto e as produções geradas, propiciando as condições para o surgimento de novas redes de pesquisa. A CAPES poderia desenvolver uma página para o PROCAD e os coordenadores ficariam responsáveis pela inserção das informações relativas aos projetos.

Entretanto, constatou-se também, a necessidade de especial atenção dos gestores do Programa, com relação aos seguintes quesitos do questionário:

Item 9 - As metas prometidas nos projetos são muito otimistas;

- Item 12 - A divulgação dos resultados da análise das prestações de contas tem sido feita com rapidez.

Nos dois quesitos cerca de $50 \%$ dos coordenadores responderam concordo parcialmente e concordo totalmente, demonstrando a necessidade de mudanças de rumo com relação aos aspectos mencionados.

Por outro lado, algumas mudanças introduzidas na Edição de 2013 merecem reflexão. A extinção das bolsas de mestrado e doutorado sanduíche reduz a mobilidade discente entre as equipes; a centralização dos recursos na figura do coordenador geral ocasiona a falta de autonomia dos coordenadores vinculados aos programas em consolidação e o considerável aumento do valor do financiamento de cada projeto em detrimento da quantidade de propostas apoiadas, resultou no indeferimento de 120 propostas recomendadas na análise de mérito.

Em estudo semelhante, abrangendo apenas a Edição PROCAD-NF 2007, ROCHA NETO \& GOMES (2011) destacam a relevância do Programa para o desenvolvimento de pesquisas de ponta e a formação de pessoal altamente qualificado, incentivando a criação de redes e contribuindo para a redução das desigualdades regionais na pós-graduação. Recomendam, ainda, a continuidade do Programa, bem como a sua ampliação favorecendo a formação de redes de pesquisa, especialmente, nas regiões Norte, Nordeste e Centro-Oeste, abrangendo áreas consideradas estratégicas para o desenvolvimento do país e tecnologias portadoras de futuro, tais como nanotecnologia, biotecnologia, tecnologia da informação e comunicação, energia e as tecnologias ambientais.

\section{CONCLUSÕES}

É possível afirmar, com base na análise feita, que o PROCAD é um instrumento de política pública que tem estimulado fortemente a interação entre os pesquisadores, a mobilidade acadêmica, a produção de conhecimentos de forma conjunta e a formação de recursos humanos de alto nível, e, consequentemente, 
tem contribuído para a consolidação de programas de pós-graduação e a redução das assimetrias regionais do país.

Pode-se assegurar que o PROCAD tem uma boa aceitação por parte da comunidade acadêmica, entretanto, outros possíveis caminhos para a sua melhoria deveriam ser analisados. A seguir, são feitas algumas proposições.

O PROCAD poderia deixar de fazer parte do rol das ações desenvolvidas por meio de editais e se tornar um programa institucional, nos moldes dos programas tradicionais da CAPES, tais como Demanda Social - DS, Programa de Apoio à PósGraduação - PROAP e Programa de Suporte à Pós-Graduação de Instituições de Ensino Particular - PROSUP. Com tal alteração o seu orçamento anual estaria garantido e poderia ser estabelecido previamente um calendário para apresentação de novas propostas, com periodicidade trienal. Neste formato, a vigência dos projetos passaria a ser de três anos.

O estabelecimento de parcerias, no âmbito do PROCAD, envolvendo também a participação de grupos vinculados a universidades estrangeiras poderia contribuir para o fortalecimento dos programas de pós-graduação brasileiros, com relação ao principal critério utilizado pela avaliação da CAPES para considerar um programa de excelência, ou seja, a internacionalização.

Por fim, esta avaliação poderá oferecer subsídios aos gestores do Programa na CAPES para a tomada de decisão com relação ao aprimoramento do PROCAD e, possivelmente, trazer reflexões acerca da necessidade de criação de um processo sistemático de avaliação não só para o PROCAD, mas para todos os programas de fomento da CAPES, além de servir como um retorno à academia quanto às ações institucionais desenvolvidas em prol do desenvolvimento científico e tecnológico.

\section{REFERÊNCIAS}

BARDIN, L. Análise de conteúdo. Tradução de Luís Antero Reto; Augusto Pinheiro. São Paulo: Edições 70, 2011.

BRASIL. Controladoria Geral da União. Diárias e passagens - perguntas e respostas. Brasília: CGU, 2012. Disponível em http://www. cgu.gov.br/Publicações/auditoria-e-fiscalização/arquivos/diariaspassagens.pdf.

Acesso em: 25 ago. 2014.

BRASIL. Decreto no 6.907, de 21 de julho de 2009. Altera dispositivos dos Decretos nos 71.733, de 18 de janeiro de 1973, 825, de 28 de maio de 1993, 4.307, de 18 de julho de 2002, e 5.992, de 19 de dezembro de 2006, que dispõem sobre diárias de servidores e de militares.

BRASIL. Ministério da Ciência e Tecnologia. Conselho Nacional de Desenvolvimento Científico e Tecnológico. RN 040, de 30/10/2013, que estabelece valores de diárias para auxílios individuais e bolsas de curta duração (País e Exterior). Diário Oficial da União, Brasília, 2013b. Disponível em http://www.cnpq.br/web/guest/view//journal_content/56_INSTANCE_0oED/10157/1318146. Acesso em: 25 ago. 2014.

BRASIL. Ministério da Educação. Coordenação de Aperfeiçoamento de Pessoal de Nível Superior. Instruções para apresentação de projetos do programa nacional de cooperação acadêmica Amazônia: edital PROCAD no 01/2006. Brasília: CAPES, 2006. 
. Instruções para apresentação de projetos do programa nacional de cooperação acadêmica: edital PROCAD no 01/2005. Brasília: CAPES, 2005c.

. Instruções para apresentação de projetos do programa nacional de cooperação acadêmica - PROCAD 2001. Brasília: CAPES, 2001.

262p.

Plano Nacional de Pós-Graduação 2005-2010. Brasília: CAPES, 2005a,

Plano Nacional de Pós-Graduação 2011-2020. Brasília: CAPES, vol. 1, 2010. Disponível em <http://www.capes.gov.br/images/stories/download/LivrosPNPG-Volume-I-Mont.pdf>. Acesso em 15 ago. 2014.

III Plano Nacional de Pós-Graduação. Brasília: CAPES, 1985. In: Brasil. Ministério da Educação. Coordenação de Aperfeiçoamento de Pessoal de Nível Superior. Plano Nacional de Pós-Graduação 2005-2010. Brasília: CAPES, 2005b, $262 p$.

Programa nacional de cooperação acadêmica: edital no 071/2013. Brasília: CAPES, 2013a.

CAPES. Relatório de gestão da CAPES: 2004-2010. Brasília: CAPES, 2010a.

. Relatório técnico dos editais PROCAD. Brasília, 2010b.

CAPES/CPE. Relatório de atividades da Coordenação de Programas Especiais 2004. Brasília, 2004.

2003.

Relatório final da avaliação do PROCAD 2000 e PROCAD 2001. Brasília,

Relatório técnico do edital no 071/2013 PROCAD. Brasília, 2015b.

Relatório técnico programas de cooperação acadêmica. Brasília, 2015a.

GOMES, D. B. B. A.; ROCHA NETO, I. Avaliação de progresso do programa nacional de cooperação acadêmica - novas fronteiras - edição 2007 e oportunidades de formação de redes cooperativas nas áreas estratégicas e tecnologias portadoras de futuro. In: Revista Brasileira de Educação, v.16, n.48. Brasília: 2011. Disponível em <www.scielo.br/pdf/rbedu/v16n48/v16n48a10.pdf>. Acesso em 15 ago. 2014.

MINAYO, Maria Cecília de Souza (Org.). Pesquisa social: teoria, método e criatividade. 31. ed. Petrópolis, RJ: Vozes, 2012.

MOROSINI, M. C.; FRANCO, M. E. D. P. Gestão de redes de pesquisa em Educação Superior: questão de princípios e ethos. In: FRANCO, M. E. D. P; MOROSINI, M. C. (Org.). Redes acadêmicas e produção do conhecimento em 
educação superior. Brasília: Instituto Nacional de Estudos e Pesquisas Educacionais, 2001.

NEVES, C. E. B. Institucionalização da pesquisa e sistemas decisórios. In: FRANCO, M. E. D. P; MOROSINI, M. C. (Org.). Universidade e pesquisa: políticas, discursos e práticas. Passo Fundo: UPF, 1999.

ROSSONI, L.; FILHO, E.R.G. Cooperação entre programas de pós-graduação em Administração no Brasil: evidências estruturais em quatro Áreas temáticas. In: RAC, v. 13, n. 3, art.2, p. 366-390. Curitiba, 2009. Disponível em <www.anpad.org.br/rac>. Acesso em: 10 set. 2014. 